\title{
Effective New Product Ideation: IDEATRIZ Methodology
}

\author{
Marco A. de Carvalho \\ Universidade Tecnológica Federal do Paraná, Mechanical Engineering Department, \\ Av. Sete de Setembro 3165, 80230-901 Curitiba PR, Brazil \\ marcoaurelio@utfpr.edu.br
}

\begin{abstract}
It is widely recognized that innovation is an activity of strategic importance. However, organizations seeking to be innovative face many dilemmas. Perhaps the main one is that, though it is necessary to innovate, innovation is a highly risky activity. In this paper, we explore the origin of product innovation, which is new product ideation. We discuss new product ideation approaches and their effectiveness and provide a description of an effective new product ideation methodology.
\end{abstract}

Keywords: Product Development Management, New Product Ideation, TRIZ.

\section{Introduction}

Introducing new products is one of the most important activities of companies. There is a significant correlation between innovative firms and leadership status [1]. On the other hand, evidence shows that most of the new products introduced fail [2].

There are many reasons for market failures of new products. This paper deals with one of the main potential sources for success or failure in new products: the quality of new product ideation. Ideation is at the start of product innovation, as recognized by eminent authors in the field such as Cooper [1], Otto \& Wood [3], Crawford \& Di Benedetto [4], and Pahl, Beitz et al. [5].

According to the 2005 Arthur D. Little innovation study [6], idea management has a strong impact on the increase in sales associated to new products. This impact is measured as an extra 7.2 percent of sales from new products and makes the case for giving more attention to new product ideation.

Ideally, only successful new product ideas should be generated. Thus, no resources would be wasted in developing products with little or no chance of market success. The problem is, how to assess if a product will be successful or not? Is it possible to determine that beforehand? These are the questions of our research.

More precisely, in this paper we seek to identify the elements of an effective new product ideation method - one that could consistently lead to valuable new product ideas. A description of such approach is also provided.

\section{New Product Idea Sources}

Essentially, there are two major new product idea sources: External and Internal. External sources are based on the use of some form of market-derived information. Internal sources rely on employee creativity. 
External new product idea sources are highly valued in new product development literature $[7,8,9]$. They include the subcategories Voice of the Customer, Open Innovation and Other.

The Voice of the Customer subcategory is composed by Ethnography, Customer Visit Teams, Customer Focus Groups, Lead User Analysis, Customer as Designer, Customer Brainstorming, Customer Advisory Boards, and Communities of Enthusiasts.

Open Innovation includes Partners and Vendors, External Scientific/Technical Community, Small Businesses and Start-ups, External Finished Product Designs, External Submission of Ideas and External Idea Contests.

Other external new product idea sources are Peripheral Vision, Disruptive Technologies, and Patent Mapping.

Internal new product idea sources contain Internal Idea Capture Systems and the wealth of Idea Generation Techniques (IGTs).

Cooper \& Edgett [10] conducted a survey on new product ideation methods. They investigated how extensively each ideation method is used - the popularity of each method - as well as management's perception of the method's effectiveness in generating high-valued new product ideas. The results are shown in Fig. 1. Each ideation method is quickly reviewed below, as well as its resulting evaluation.

Voice of the Customer methods are among the highest in both popularity and effectiveness. Ethnography entails cohabitating with customers using a product. This is done for a relatively extended period of time. The objective is to discover unmet and unarticulated needs, new product applications and problems. The application of this method is effective, but not very popular, because it is not well suited for all markets and product types and requires highly experienced researchers as implementers.

Customer Visit Teams are multi-functional teams that visit customers and use carefully prepared interviews to uncover product-related problems and needs. It was considered both popular and effective by survey respondents.

In Customer Focus Groups, customers are gathered and a skilled moderator focuses their discussion on problems or wants. It is also a popular and effective idea generation method.

Lead User Analysis, systematized by Von Hippel [11] involves identifying, negotiating with and working closely with lead users. Lead users are customers that today have specific needs which have the potential to become general market needs in the future. This method is considered highly popular and effective.

In the Customer as Designer method, customers perform part of the product development. They are provided with a kit, which they use to customize the product as desired. This method is considered highly effective but not very popular. The reason is that, though it relies on input by very specialized and informed customers, is can not be applied to a wide variety of products.

Customer Brainstorming can be used for involving customers both in expliciting product problems and in generating new product ideas. It is a highly effective and moderately popular method.

Customer Advisory Boards are group of strategic customers that meet to offer advice on products (problems and needs) and also on company strategy. Customer Advisory Boards are moderately popular and effective, according to the survey. 


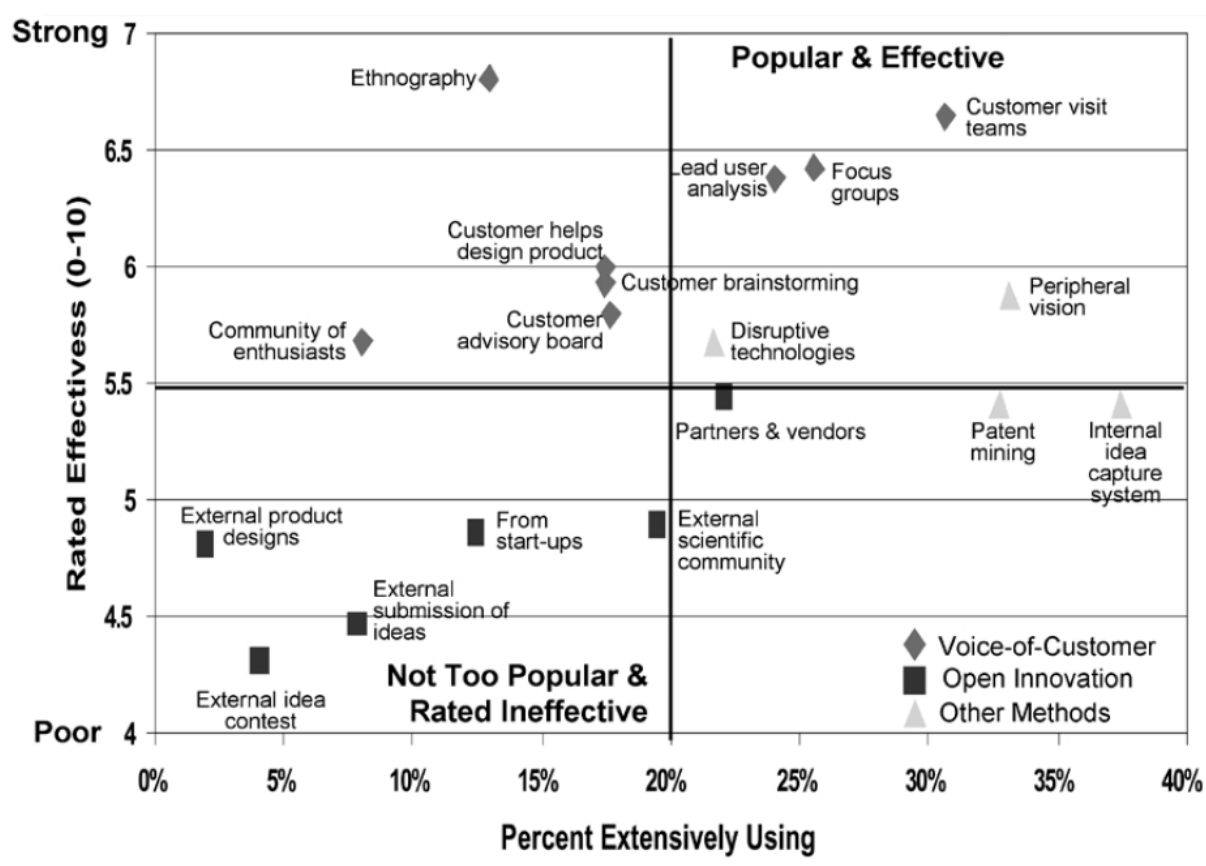

Fig. 1. Effectiveness and popularity of ideation methods [10]

Communities of Enthusiasts are increasingly common. They are usually organized on the internet. Enthusiasts discuss a product, often uncovering problems and generating ideas. This method is not considered very effective or popular.

According to Cooper \& Edgett [10], Open Innovation approaches are neither very popular nor very effective. Seeking new product ideas from Partners and Vendors is the most popular amongst them. Accessing the External Scientific/Technical Community is considered a relatively popular, but not very effective approach.

Small Businesses and Start-ups can be a good source of ideas, especially considering that breakthrough innovations frequently come from smaller companies. However, the popularity and effectiveness was considered relatively low in the survey.

Seeking External Finished Product Designs is not widely used by research respondents, and thus had low popularity and effectiveness evaluations.

External Submission of Ideas and External Idea Contests are similar approaches, both low on popularity and effectiveness.

"Other" external new product idea sources - Peripheral Vision, Disruptive Technologies, and Patent Mapping - have moderate effectiveness and moderate to high popularity.

Peripheral Vision is an assessment of external trends and threats that can lead to new product ideas. It is very popular and moderately effective.

Disruptive Technologies is a method focused on scanning technologies that have the potential to become disruptive - a special case of the threats assessment of Peripheral Vision - and defining new product ideas from them. This method is fairly popular and moderately effective. 
Patent Mapping is the mapping or mining of competitor's patents with the objective of finding potential areas for introducing new products. It is a popular and moderately effective approach.

Internal new product ideation sources involve the use of organizational resources to generate new product ideas. In Cooper \& Edgett's survey, Internal Idea Capture Systems came up as the most popular ideation approach. However, this was not considered a very effective method.

\section{Critique of the External New Product Idea Source Bias}

As seen in previous session, marketing theory focuses on many different ways to exhaust the External source of new product ideas - the market. However, historic data reveals that many new and surprising product ideas were devised by people that had absolutely no knowledge about what later would become the market for those products.

With the exception of very simple products and extensions, product development takes considerable effort and time. Hence, designing products based solely on voice of the customer studies and need assessments made at the initial stages of product development means that the latter will be designed for the past. Clearly, the External source can provide only indications about the past $[8,11]$.

According to Ries \& Trout [12], most marketing surveys are reports on the past. Market research tells what customers already did and wanted, and not necessarily what they will do and want. Ottoson \& Nordin [13] stated that innovation and the voice of the customer (Quality Function Deployment) are like fire and water.

Goldenberg \& Efroni [14] proposed that it is of no use to look for new product ideas in the market, because:

- it is impossible to extract new and surprising ideas from a latent market, since at this stage the market is not yet aware an can not provide information about them;

- it is useless to extract information from a market saturated with information about a particular product, for the simple reason that the information extracted will not be innovative or surprising.

As a means to compensate for the lack of timeliness of market information in new product development, some authors $[15,16,17]$ have tried a somewhat different approach to explore the External source for new product ideas: compiling and using market trends. Arguably, market trends indicate future customer's needs. However, market trends are very generic, rendering them of limited usefulness in new product ideation. This becomes especially true when they are compared with the heuristic IGTs, discussed in the next session.

We are critical of the excessive focus on the External ideation approach that prevails in marketing literature. The absence of reference to IGTs in Cooper \& Edgett's research seems to be a symptom of that. We defend that IGTs can be an effective new product ideation approach, because our experience shows that their use can result in genuinely original ideas. 


\section{Idea Generation Techniques and Their Effectiveness}

We have been experimenting with the effectiveness of IGTs since 1997.

There are hundreds of IGTs, which makes experimenting with each one of them impractical. However, when a closer look was taken at the vast variety of techniques, it became apparent that there are many similarities. Thus, we considered that a smaller study could be done, focusing only on representative techniques. After analyzing the literature on IGTs, we considered these techniques as representative of:

- intuitive IGTs: Brainstorming [18], Brainwriting [19], Synectics [20], Lateral Thinking (LT) [21], and Gallery [21];

- systematic IGTs: Value Analysis (VA) [23], and Morphological Method (MM) [24];

- heuristic IGTs: Inventive Principles (IP) [25], Separation Principles (SP) [25], Smart Little People (SLP) [25], 121 Heuristics (121H) [26], Evolution Trends (ET) [27], Su-Field Analysis and Standards (SUF) [25], and ARIZ [25].

The experiments applying selected IGTs where conducted between 1997 and 2007, in training environments. Participants were undergraduate students and young professionals in different technical careers. Mainly, participants came from these areas: mechanical, electrical and civil engineering, and product design.

The general procedure for each experiment was:

1. Instruction about the specific IGT by the author;

2. Application of the IGT by teams of 4 to 6 training participants, under author's supervision, with support of a standard form, specifically created for each IGT;

3. Evaluation of results (ideas generated) by the teams, and discussion involving all teams;

4. Evaluation of ideas by external experts in the subject area of each application.

The underlying concept for the last evaluation is that a creative idea is one that is both original and useful, as judged by domain experts [28]. This is based on the assumption that people, and especially experts, can identify a creative idea, even when they are unable to supply a list of properties which characterize a creative idea in their domain.

The results are summarized in Table 1 [29]. Table 1 includes total number of experiments, the size of the sample analyzed (about $30 \%$ of experiments), and the statistics of interest: number of generated ideas, number of original ideas, number of useful ideas, and number and percentage of creative ideas. A discussion of the results is provided below.

Experiments with Brainstorming resulted in 17,3\% creative ideas, in average. Originality was 33,9\% in average, and usefulness, 25,5\% in average. For instance, in a Brainstorming session focused on the problem of paint removal from a wall, not very practical ideas such as "use cats to scratch paint" and "use nano-technological paint remover" were suggested. In a typical Brainstorming session, ideas that negate or change the initial objective are often proposed, such as "use materials that make painting unnecessary", "no paint", and "eliminate walls". Experiments made evident that good results in Brainstorming are highly dependent on the team's profile and moderator action. Average time demanded for preliminary analysis and selection of generated ideas was 162 minutes, more than 3 times the average ideation time of 49 minutes. 
Table 1. Results of experiments with IGTs [29]

\begin{tabular}{|c|c|c|c|c|c|c|c|c|c|c|c|}
\hline \multirow[b]{2}{*}{ છ } & \multirow{2}{*}{ 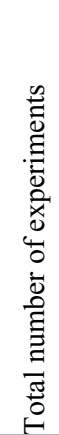 } & \multirow{2}{*}{ 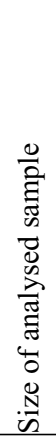 } & \multicolumn{2}{|c|}{ 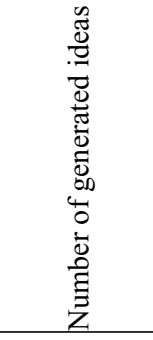 } & \multicolumn{2}{|c|}{$\bar{z}$} & & \multicolumn{2}{|c|}{ 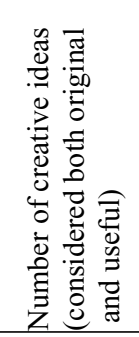 } & \multirow{2}{*}{ 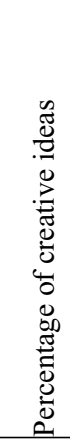 } \\
\hline & & & $\pi$ & & $\pi$ & $\infty$ & $\pi$ & & $\pi$ & in & \\
\hline Brainstorming & 160 & 30 & 58,5 & 13,9 & 33,9 & 10,5 & 25,5 & 4,3 & 10,1 & 4,2 & 17,3 \\
\hline Brainwriting & 160 & 30 & 91,3 & 8,1 & 45,3 & 13,9 & 27,2 & 8,5 & 15,5 & 8,2 & 17,0 \\
\hline Synectics & 150 & 27 & 44,5 & 8,7 & 30,8 & 9,3 & 13,5 & 4,1 & 9,2 & 3,7 & 20,6 \\
\hline LT & 130 & 25 & 27,8 & 6,3 & 18,9 & 6,2 & 12,8 & 5,2 & 4,5 & 2,1 & 16,2 \\
\hline Gallery & 130 & 25 & 49,1 & 9,7 & 24,6 & 6,8 & 11,0 & 5,8 & 6,3 & 3,8 & 12,8 \\
\hline VA & 109 & 20 & 22,3 & 7,1 & 12,7 & 5,9 & 15,4 & 4,4 & 5,2 & 1,8 & 23,3 \\
\hline MM & 160 & 30 & 20,8 & 6,6 & 6,2 & 3,2 & 12,2 & 3,6 & 4,2 & 2,0 & 20,1 \\
\hline IP & 89 & 17 & 23,1 & 6,3 & 15,7 & 5,1 & 13,8 & 4,2 & 7,6 & 3,2 & 32,9 \\
\hline SP & 14 & 3 & 18,5 & 4,2 & 12,3 & 3,4 & 8,0 & 3,7 & 6,4 & 2,6 & 34,6 \\
\hline SLP & 14 & 3 & 14,3 & 4,4 & 11,2 & 3,1 & 6,7 & 2,3 & 5,2 & 1,8 & 36,3 \\
\hline $121 \mathrm{H}$ & 14 & 3 & 27,5 & 8,2 & 17,9 & 6,2 & 12,2 & 5,2 & 8,5 & 2,6 & 30,9 \\
\hline ET & 14 & 3 & 55,0 & 12,1 & 30,3 & 9,6 & 17,3 & 7,2 & 15,2 & 3,2 & 27,6 \\
\hline SUF & 14 & 3 & 13,5 & 3,2 & 7,5 & 3,3 & 6,0 & 2,2 & 7,2 & 2,7 & 53,3 \\
\hline ARIZ & 14 & 3 & 14,2 & 3,5 & 6,4 & 3,0 & 5,3 & 2,0 & 7,4 & 2,1 & 52,1 \\
\hline
\end{tabular}

Brainwriting results were similar to those obtained with Brainstorming: $17,0 \%$ of creative ideas. We found evidence contrary to Hellfritz's observations [22]: in our experiments, when compared to Brainstorming, Brainwriting frequently resulted in a bigger number of ideas generated - and thus, to more idea evaluation work.

Regarding Synectics, our experience is in general accordance with Altshuller's observation [30] that it is more effective than Brainstorming (average of 20,6\% creative ideas against Brainstorming's 17,3\%). We observed that Synectics fosters a better understanding of the problem. Besides that, Synectics uses analogies, which tend to result in more original ideas [31]. The smaller number of ideas generated tends to reduce the evaluation time.

Results obtained with Lateral Thinking (average of 16,2\% creative ideas) were similar to Brainstorming ones (17,3\%).

For the Gallery method, we expected results similar to the ones obtained with Brainwriting. After all, Gallery is very similar to Brainwriting, with the difference that ideas are not described in text, but drawn. However, the average of creative ideas was $12,8 \%$, significantly below Brainwriting's 17,0\%. We suspect that the reason might be that Gallery's procedure is more prone to foster adherence to particular thinking patterns and make it more difficult to explore ideas outside those established paths. 
Value Analysis tends to result in moderately creative ideas (average of 23,3\%). Ideas tend to be focused on the most important problems in a product, as identified in the "problem analysis" phase of the procedure. Ideas are generated in a relatively smaller number, in accordance with a checklist. This makes the evaluation process easier. On the other hand, because of the very nature of the method, resulting ideas are mostly focused on a product's subsystems and parts, and not an entire new product idea [29].

The Morphologic Method resulted in an average of 20,1\% creative ideas. The main disadvantage of this IGT is the time it takes for careful parameter definition, research and/or idea generation for each parameter and skillful combination, so as to maximize the exploration of different ideas while still minimizing the evaluation effort [29].

Heuristic methods tend to require significant time. In our experience, the shortest was a 30 minutes Separation Principles session and the longest, a 350 minutes ARIZ session. The average time for all heuristic IGT sessions was 110 minutes. However, what could be considered a high time investment pays itself. These IGTs are among the highest in creativity, varying between $27,6 \%$ creative ideas for Evolution Trends and 53,3\% for Su-Field Analysis and Standards [29].

\section{Elements of an Effective New Product Ideation Approach}

Considering the arguments presented in session 3, we concluded that a more effective new product ideation approach should not be based on the External, but on the Internal source (IGTs). Moreover, the experiments described in session 4 provided evidence that the most effective IGTs, with the highest creativity scores, are the heuristic ones. This is also supported by previous research conducted by Horowitz \& Maimon [32].

However effective, by experience, we know that heuristic IGTs are not ready for use in new product ideation in their original state. With their strength comes a congenital problem: heuristics were derived mainly from patent information [30]. Hence, they are well connected with technology evolution patterns, but not necessarily to customer's potential interests. As a consequence, if the heuristics are used directly for new product ideation, a significant amount of work is left to the idea selection phase, at which point a long process of filtering out ideas not potentially interesting to customers must happen.

We considered that three main concepts would allow taking advantage of the heuristic methods' strengths and avoiding their weaknesses in our new product ideation approach:

- the concept of value [23] as the main guideline for new product ideation;

- the concept of the voice of the product [33] as a more effective means of adding knowledge about the market to the ideation process;

- the concept of disruptive innovation [34] as a way of considering that innovation can also be achieved by low-end and new-market disruptions.

Value, first formulated by Lawrence D. Miles [23], makes it clear that customers are generally interested in more and better functions and/or the lowest possible associated costs. Yezersky [35] united the concept of value and the use of heuristics in his General Theory of Innovation (GTI) - in that case, for the finality of technological forecasting. 
Another contribution of Yezersky's GTI [35] was the notion that value can be stated as the reason between functions and connections. In the initial phases of product development - and even more so in ideation - information about cost is scarce. Hence, the original value equation's denominator, cost, can be advantageously replaced by connections - conduits that allow energy, matter and information flows between a system's elements, and between one system and other systems or users. For ideation purposes, it is more effective to think of connections than cost.

According to Goldenberg et al. [33], products evolve in response to environmental pressures. These are represented by customer's needs. Products that do not satisfy customer's needs disappear, while the ones that do survive, at least until there is a new environmental change. As a result, customer's needs are mapped or coded into a company's products. Generating ideas from these, by imagining transformations of current products, or "listening to the voice of the product" is thus an effective means of generating new product ideas with a minimum of formally researched market information.

The disruptive innovation concept was proposed by Christensen [34]. In short, it is an innovation that the market does not expect, because the prevalent industry paradigm of increasing functions and improving performance is not followed. Typically, disruptive innovation is lower priced (low-end disruption) or designed for a different set of consumers (new-market disruption). A low-end disruptive innovation is aimed at mainstream customers for whom price is more important than quality. A newmarket disruptive innovation is often aimed at consumers who would not have used the products already on the market.

\section{Proposed New Product Ideation Approach}

Based on the reasoning described previously, we devised a new product ideation methodology we chose to name IDEATRIZ, illustrated in Fig. 2.

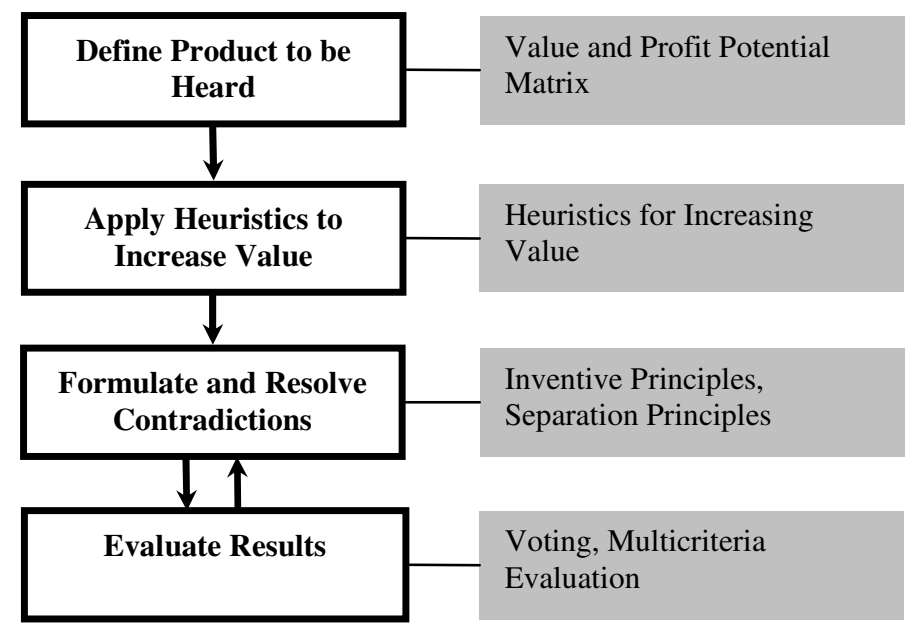

Fig. 2. IDEATRIZ New Product Ideation Methodology Phases and Tools [29] 
Since it is based on the voice of the product concept, IDEATRIZ starts with the definition of the product to be heard. Then, heuristics are used with the purpose of generating ideas that increase value. Many good ideas generated via heuristics have disadvantages. In the third phase, these are explicited in terms of contradictions and solutions are sought. Finally, results are evaluated and new product ideas to be implemented are chosen. Each phase is described in more detail below.

\subsection{Define Product to Be Heard}

Any product can be the focus product for ideation. However, positioning the company's current products along a Value and Potential Profit Matrix (Fig. 3) can be quite useful to subsidize this decision.

In the Matrix, two dimensions are considered: the profit potential of the market and the relative value provided by the product in relation to competitive offers. The target quadrant is the high profit potential and high value. The priority candidates for ideation can vary according to the company's strategy, but in general are products:

1. In the high profit potential and low value to customers quadrant. In this case, the objective is to increase value provided by the product in relation to competitors;

2. In the low profit potential and high value to customers quadrant. Here, the goal is to ideate means to penetrate in new, higher potential markets.

3. In the low profit potential and low value to customers quadrant. In this case, both means to increase value and penetrate higher potential markets are needed.

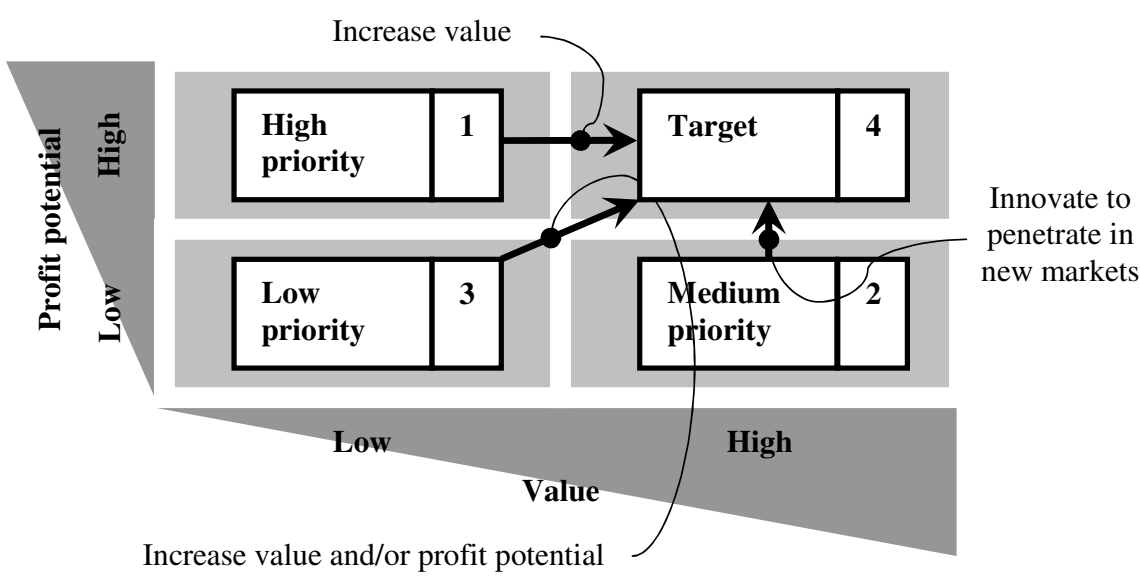

Fig. 3. Value and Potential Profit Matrix [29]

Other possible focus product for ideation candidates are those not previously introduced in the market for viability reasons, but whose moment might have arrived [36]. 


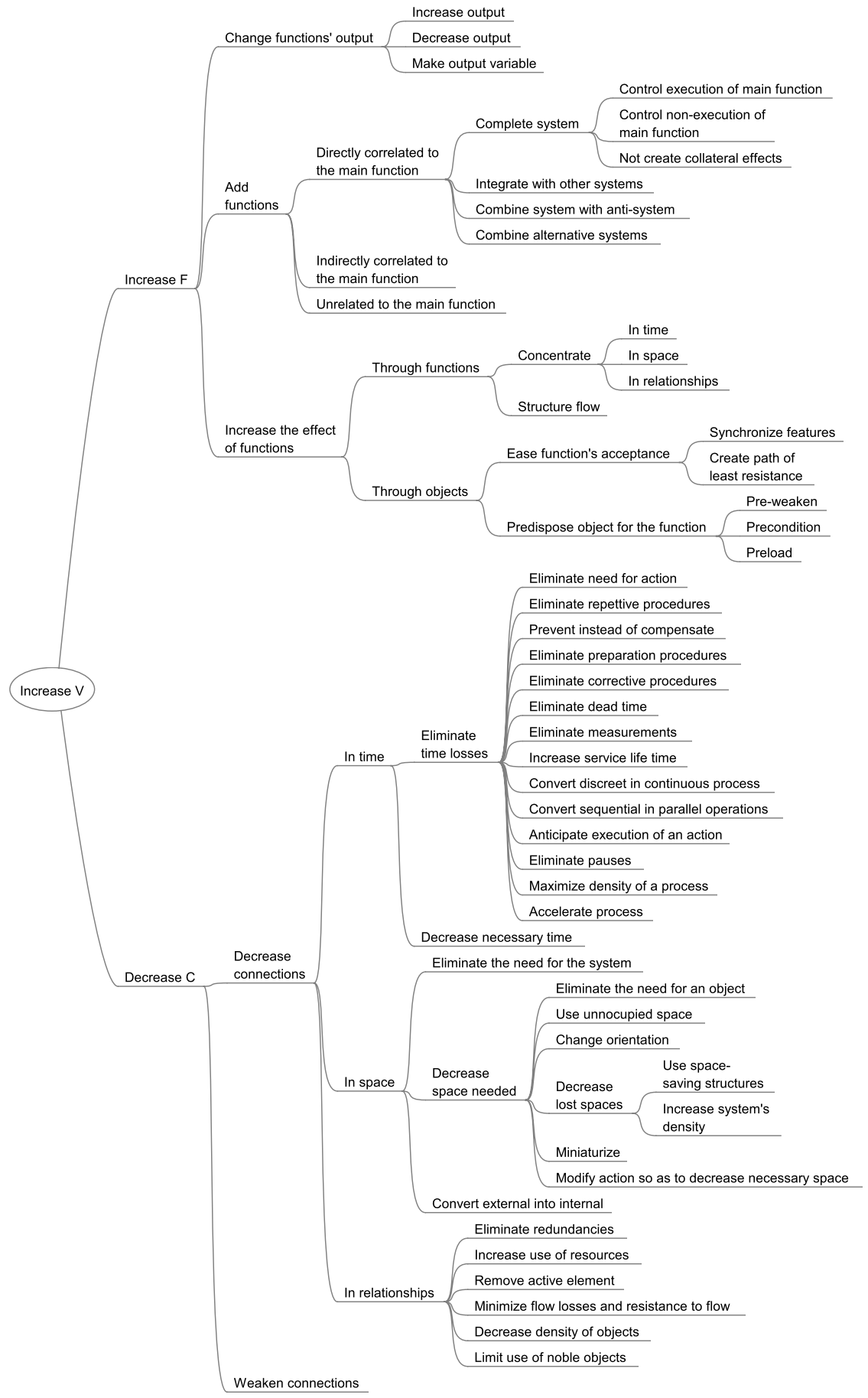

Fig. 4. Heuristics to Increase Value [29] 


\subsection{Apply Heuristics to Increase Value}

As previously discussed, increase of value can be achieved, in general, through increase of functions and decrease of connections. More specifically, the following alternatives might be considered as the ideation goal:

1. Maintain current functions and reduce connections;

2. Increase the quantity and/or quality of functions and maintain connections;

3. Increase the quantity and/or quality of functions and increase connections, in a proportion acceptable by customers;

4. Increase the quantity and/or quality of functions and reduce connections;

5. Decrease the quantity and/or quality of functions and decrease connections, in a proportion acceptable by customers.

Once the general ideation alternative is defined, heuristics should be used for ideation. IDEATRIZ heuristics are summarized in Fig. 4.

IDEATRIZ heuristics are inspired by Yezersky's proposition for technological forecasting [35]. They derive from TRIZ-related heuristics such as the Inventive Principles [25], Separation Principles [25], 121 Heuristics [26], Evolution Trends [27], and Standards [25]. Only those heuristics clearly pointing to the value maximization goal were included.

Heuristics such as Mann's "Increase Use of Colour" Evolution Trend [27] were not included. Although such heuristics might result in new product ideas, they do not necessarily indicate the direction of increased functions and/or decreased connections. Evidence in this regard can be found in Bogéa et al. [37] and Da Rocha \& De Carvalho [38].

\subsection{Formulate and Resolve Contradictions}

The previous phase results in ideas with potential to increase value. Some of those will have disadvantages. Our proposition is not to discard them immediately only because of the drawbacks, but to formulate and resolve the associated contradictions, using the Inventive Principles and/or Separation Principles.

\subsection{Evaluate Results}

IDEATRIZ final phase involves evaluation and selection of the best ideas for implementation. If 15 ideas or more were generated, we suggest a two-step evaluation process, beginning with voting. The voting should be done in such a way as to allow only 15 or less ideas to proceed to the second step.

The second step involves multicriteria evaluation, using the criteria shown in Table 2. The suggested scale ranges from 1 to 5: very bad (1), bad (2), medium (3), good (4), and very good (5). 
Table 2. Evaluation phase criteria [29]

\begin{tabular}{|c|c|}
\hline - Criteria & - Aspects to Consider While Evaluating \\
\hline $\begin{array}{l}\text { - Atractivity and } \\
\text { benefits }\end{array}$ & $\begin{array}{l}\text { - Is the potential market for the idea attractive, in size and } \\
\text { potential growth? What is the probability of pay-off? What is } \\
\text { the expected return on investment? Are there additional } \\
\text { benefits, such as compliance with legal requirements and } \\
\text { know-how that can be used in other projects? }\end{array}$ \\
\hline - Alignment & $\begin{array}{l}\text { - Is the idea aligned to the company's strategy? Are there } \\
\text { synergies with the current product and service portfolio? Does } \\
\text { the company have the necessary technology, considering the } \\
\text { whole life cycle? }\end{array}$ \\
\hline - Originality & $\begin{array}{l}\text { - Is the idea original? Are there advantages that can be easily } \\
\text { and clearly perceived by the customer, when competitive } \\
\text { offers are considered? }\end{array}$ \\
\hline - Precocity & $\begin{array}{l}\text { - What is the estimated time to implement the idea, to } \\
\text { implement it and to establish it in the market? Is there the } \\
\text { possibility of being a pioneer? }\end{array}$ \\
\hline $\begin{array}{l}\text { - Durability of } \\
\text { advantage }\end{array}$ & $\begin{array}{l}\text { How big are the barriers to new entrants? How difficult is } \\
\text { it to copy the idea? Is it possible to protect the idea, either } \\
\text { through patent or other strategy? }\end{array}$ \\
\hline $\begin{array}{l}- \text { Life cycle } \\
\text { duration }\end{array}$ & $\begin{array}{l}\text { - What is the market's phase in its life cycle? What is the } \\
\text { estimate life of the product that will result from the idea? }\end{array}$ \\
\hline - Investiment & $\begin{array}{l}\text { - What is the estimated investment to embody the idea, } \\
\text { considering the whole life cycle? }\end{array}$ \\
\hline - Sustainability & $\begin{array}{l}\text { - Is the idea sustainable in social, environmental and } \\
\text { economic aspects? }\end{array}$ \\
\hline - Risk & $\begin{array}{l}\text { - Is it possible to embody the idea? What is the risk of } \\
\text { adverse regulations? Are there oter risks that need to be } \\
\text { considered? }\end{array}$ \\
\hline
\end{tabular}

\section{Conclusions}

The ideal of only generating successful new product ideas was not attained. However, a step closer to this ideal was reached. We have devised an ideation methodology based on the most effective ideation elements.

The IDEATRIZ methodology is undergoing tests in real new product ideation situations, with good results. We intend to publish these in the near future.

\section{Acknowledgments}

The author expresses his gratitude to all who helped in this research, especially André Ogliari, Greg Yezersky, and the sponsors IFM (Instituto Fábrica do Milênio), CNPq (Conselho Nacional de Desenvolvimento Científico e Tecnológico) and FINEP (Financiadora de Estudos e Projetos). 


\section{References}

1. Cooper, R.G.: Winning at New Products: Accelerating the Process from Idea to Launch. Basic Books (2001)

2. Christensen, C.M., Raynor, M.E.: The Innovators Solution: Creating and Sustaining Successful Growth. Harvard University Press, Cambridge (2003)

3. Otto, K.N., Wood, K.L.: Product Design: Techniques in Reverse Engineering and New Product Development. Prentice-Hall, Upper Saddle River (2001)

4. Crawford, C.M., Di Benedetto, C.A.: New Products Management. McGraw-Hill, New York (2003)

5. Pahl, G., Beitz, W., Feldhusen, J., Grote, K.-H.: Engineering Design: A Systematic Approach. Springer, Berlin (2007)

6. Little, A.D.: How Companies Use Innovation to Improve Profitability and Growth (Innovation Excellence Study). Arthur D. Little, Boston (2005)

7. Urban, G.L., Hauser, J.R.: Design and Marketing of New Products. Prentice-Hall, New Jersey (1993)

8. Griffin, A.: Obtaining Customer Needs for Product Development. In: Kahn, K.B., Castellion, G., Griffin, A. (eds.) The PDMA Handbook of New Product Development. Wiley, Hoboken (2005)

9. Cooper, R.G., Edgett, S.J.: Generating Breakthrough New Product Ideas: Feeding the Innovation Funnel. Product Development Institute, Ancaster (2007)

10. Cooper, R.G., Edgett, S.J.: Ideation for Product Innovation: What Are the Best Methods? PDMA Visions Magazine 1, 12-17 (2008)

11. Von Hippel, E.: Democratizing Innovation. MIT Press, Cambridge (2005)

12. Ries, A., Trout, J.: Bottom-up Marketing. McGraw-Hill, New York (1989)

13. Ottosson, S., Nordin, L.: Innovation and QFD are like Fire and Water. In: International Conference on Engineering Design — ICED 1997, Tampere, Finland (1997)

14. Goldenberg, J., Efroni, S.: Using Cellular Automata Modeling of Emergence of Innovations. Technology Forecasting and Social Change 68, 293-308 (2001)

15. Popcorn, F.: The Popcorn Report. Harper Business, New York (1991)

16. Popcorn, F., Marigold, L.: Clicking. Harper Collins, New York (1997)

17. Hill, S.: Sixty Trends in Sixty Minutes. Wiley, Chichester (2002)

18. Osborn, A.F.: Applied Imagination. Charles Scribner's Sons, New York (1953)

19. Rohrbach, B.: Kreativ nach Regeln: Methode 635, eine neue Technik zum Lösen von Problemen. Absatzwitschaft 12, 73-75 (1969)

20. Gordon, W.J.J.: Synectics. Harper \& Row, New York (1961)

21. De Bono, E.: New Think: The Use of Lateral Thinking in the Generation of New Ideas. Basic Books, New York (1968)

22. Hellfritz, H.: Innovation via Galeriemethode. Eigenverlag, Königstein/Ts (1978)

23. Miles, L.D.: Techniques of Value Analysis and Engineering. McGraw-Hill, New York (1961)

24. Zwicky, F.: The Morphological Method of Analysis and Construction. Wiley-Interscience, New York (1948)

25. Altshuller, G.S., Zlotin, B., Zusman, A., Philatov, V.: Searching for New Ideas: From Insight to Methodology - The Theory and Practice of Inventive Problem Solving. Kartya Moldovenyaska, Kishinev (1989) (in Russian)

26. De Carvalho, M.A., Wei, T., Savransky, S.D.: 121 Heuristics for Solving Problems. Lulu, Morrisville (2003)

27. Mann, D.: Hands-On Systematic Innovation. CREAX, Ieper (2002) 
28. Hennessey, B.A., Amabile, T.M.: The Conditions of Creativity. In: Sterenberg, R.J. (ed.) The Nature of Creativity. Cambridge University Press, Cambridge (1988)

29. De Carvalho, M.A.: IDEATRIZ Methodology for New Product Ideation (Doctoral Thesis). PPGEP/UFSC, Florianópolis (2007) (in Portuguese)

30. Altshuller, G.S.: To Find an Idea. Nauka, Novosibirsk (1986) (in Russian)

31. Mayer, R.E.: Thinking, Problem Solving, Cognition. Freeman \& Company, New York (1992)

32. Horowitz, R., Maimon, O.: Creative Design Methodology and The SIT Method. In: Proceedings of ASME Design Engineering Technical Conference. ASME, Sacramento (1997)

33. Goldenberg, J., Mazursky, D., Solomon, S.: Templates of Original Innovation: Projecting Original Incremental Innovations from Intrinsic Information. Technological Forecasting and Social Change 11, 1-12 (1999)

34. Christensen, C.M.: The Innovator's Dillemma. HarperCollins, New York (2000)

35. Yezersky, G.: Creating Successful Innovations: General Theory of Innovation and its Applications. Institute of Professional Innovators / Università Degli Studi di Firenze, Vinci (2006)

36. Karanjikar, M.R.: Managing Failed Ideas: Could This Have Been the Next iPod? PDMA Visions Magazine 3, 14-15 (2007)

37. Bogéa, L.C., De Carvalho, M.A., Mattos, F.R., De Miranda, L.G.I.F.: Dirigindo o Futuro dos Secadores de Cabelos. In: Anais do V Congresso Brasileiro de Gestão do Desenvolvimento de Produtos. IGDP, Curitiba (2005)

38. Da Rocha, L.L.V., De Carvalho, M.A.: Análise das Tendências da Evolução dos Sistemas Técnicos como Forma de Previsão Tecnológica. In: Anais do IX Seminário de Iniciação Científica e Tecnológica do CEFET-PR. Editora do CEFET-PR, Curitiba (2004) 